\title{
A Retrospective Analysis of the Prevalence of Distribution of Oral Mucosal Lesions (OMLs) among the People of Delhi NCR
}

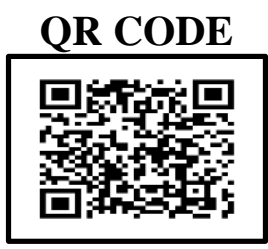

SIMRAN KAUR ${ }^{*_{1}}$, ASEEM SINGH${ }^{2}$, RAHUL SINGH $^{3}$

INTRODUCTION: The presence of Oral Mucosal Lesions (OMLs) in one's oral mucosa can lead to unwanted consequences and mostly are due to tobacco use.

AIM: To document the prevalence of OMLs among patients of Delhi NCR and provide health education counselling to those under the grip of this evil practice.

MATERIAL AND METHODS: We retrospectively analyzed the data of a total of 402 subjects visiting various screening camps in Delhi NCR and recalled a total of 174 patients, out of which 161 reported back to us for further diagnosis and screening of OMLs. The examination of patients in the camp were an ADA type III examination. All patients we given a health education while tobacco users were also given a specialized one-on-one health education regarding the tobacco and its ill effects as well as techniques for cessation. A descriptive analysis of the sample was first performed using means ( \pm standard deviation (SD)) for continuous variables and frequencies (proportions) for categorical variables. The chi-square test was used for statistical analysis and to find significant difference, if any.

RESULTS: Among the 402 subjects screened, the mean age was $33.24 \pm 6.74$ Years and most of the study population belonged to the age group of $25-60$ Years $[178(44.3 \%)] .301(74.8 \%)$ of the study population were males. The main chief complaint was periodontal problem [187(46.5\%)], while 15 patients $(3.73 \%)$ came for regular check-up. The prevalence of leukoplakia was found to be $8.70 \%$ and OSMF was found to be $6.21 \%$. A significant difference was seen among gingivitis with respect to age and gender ( $\mathrm{p}<.05$ ), leukoplakia and frictional keratosis was seen significant in relation to gender. In all significant cases, Males were more prone to get these OMLs as compared to females

CONCLUSION: It is advised that regular Oral Health Drives and counselling sessions be arranged for the people of Delhi NCR to reduce the burden of the OMLs.

KEYWORDS: Oral, Lesion, Mucosal, Leukoplakia

\section{INTRODUCTION}

A major challenge and a Public Health Burden across the globe, the ill- effect of tobacco consumption has been ever plaguing all societies across the globe. In India itself, it is estimated that approximately 275 million adults consume some form of tobacco products. ${ }^{1}$ This huge number accounts for approximately one fifth of the world's total population and the alarming picture oral pre-cancerous lesions are being seen in the younger generation. ${ }^{2,3}$

Researchers, from time and gain have been highlighting the fact that tobacco and alcohol consumption are evident risk factors for oral cancer and hence, there is a need to create awareness among these people. ${ }^{3,4}$ While people are aware of the medical effects of consuming such products, a person places little or no emphasis on his/her oral health due to variety of factors (financial constraint, lesser knowledge regarding oral health, limited resources, etc.) and is at risk of developing various Oral Mucosal Lesions (OML). ${ }^{5}$

Various processed forms of tobacco are available commercially at a very low cost (especially smokeless tobacco) and this increases it reach especially among the younger generation. As per a report of the World Bank, nearly 82,000-99,00o children and adolescents across the globe begin smoking every day and this significantly increases the risk of the presence of OMLs among them. ${ }^{6}$ Among adults, the prevalence of tobacco users is reported as $28.6 \% .^{7}$

Since the use of tobacco in India is reaching pandemic levels, it is important that this vulnerable population be regularly screened for any potential OML and be educated regarding its ill effects. Therefore, this study aimed to document the prevalence of OMLs among 
patients of Delhi NCR and provide health education counselling to those under the grip of this evil practice.

\section{MATERIALS ANS METHOD}

The study was performed by retrospectively analyzing a total of 402 oral examinations of patients visiting various dental screening and treatment camps in Delhi NCR.

After obtaining an informed consent from each participant, and explaining them the objectives of the study and the need to recall them for further examination in the dental clinic for suspected OMLs, a total of 174 patients were recalled for further examination from a total of 190 tobacco consumers. The patients were recalled phone (prior permission taken during consent) and a total of 161 patients reported to the study. Since the remaining 13 patients did not report on the day of appointment(s) (Maximum three appointments given), and in the absence of any confirmatory test, were excluded from the sample of patients with OMLs. Those OMLs not found in the study were exclude from the analysis. There were three examiners who conducted the clinical examinations and all three were duly calibrated prior to the study. All patients 402 patients screened were given health education regarding oral heath tips while the 174 suspected OML cases were also provided specialized one-on-one health education regarding the tobacco and its ill effects as well as techniques for cessation.

The examination of patients in the camp were an ADA type III examination under natural/artificial light and the recalled 161 patients were further screened in under artificial lighting on a dental chair and with a mirror. During the clinical examination, the following elements were noted: features of the lesion, anatomical site, extension, etiological or related factors, dental status, trauma, use of prosthesis, and whether or not these were well adapted. Patients who did not provide consent were excluded from the study.

All the obtained data were analyzed statistically by using a Statistical Package for Social Sciences version 21 (SPSS Inc. Chicago, IL, USA). ${ }^{8}$

A descriptive analysis of the sample was first performed using means ( \pm standard deviation (SD)) for continuous variables and frequencies (proportions) for categorical variables. Different intraoral and extraoral findings on clinical examination were reported. The chi-square test was used for statistical analysis and to find significant difference, if any.

\section{RESULTS}

The characteristics of the patients is described in table 1. It was observed that of the total 402 subjects examined, the mean age was $33.24 \pm 6.74$ Years and most of the study population belonged to the age group of 256o Years $[178(44.3 \%)]$. Most of the people who got themselves examined were males [301(74.8\%)]. Approximately half of the population [195(48.5\%)] was self-employed. It was revealed that of the total population, 197(49.0\%) people reported to be users of tobacco in any form. Most of the tobacco users [8o(40.6\%)] were found to be users of smokeless tobacco.

\begin{tabular}{|c|c|}
\hline Characteristic & Frequency $(\%)$ \\
\hline Age (Mean \pm SD) & $33.24 \pm 6.74$ \\
$<25$ Years & $155(38.5 \%)$ \\
$25-60$ Years & $178(44.3 \%)$ \\
>6o Years & $69(17.2 \%)$ \\
Total & 402 \\
\hline Gender & \\
Male & $301(74.8 \%)$ \\
Female & $101(25.2 \%)$ \\
\hline Occupation & \\
Student & $129(32.1 \%)$ \\
\hline Employed/Self Employed & $195(48.5 \%)$ \\
\hline Housewife/retired & $78(19.4 \%)$ \\
\hline Tobacco Users & $197(49.0 \%)$ \\
Smokeless & $80(40.6 \%)$ \\
Smoked & $51(25.8 \%)$ \\
Both & $66(33.6 \%)$ \\
\hline
\end{tabular}

Table 1. Characteristics of the Study Population

\begin{tabular}{|c|c|}
\hline Chief Complaint & Frequency (\%) \\
\hline Pain & $113(28.1 \%)$ \\
\hline Dental Hard Tissues & $51(45.1 \%)$ \\
Dental Soft Tissues & $47(39.6 \%)$ \\
Other Pain & $15(13.3 \%)$ \\
\hline Restorations & $58(14.4 \%)$ \\
Required & $52(89.7 \%)$ \\
Faulty & $6(10.3 \%)$ \\
\hline Prosthesis & $29(7.3 \%)$ \\
\hline Required & $25(86.2 \%)$ \\
Faulty & $4(13.8 \%)$ \\
\hline Periodontitis & $187(46.5 \%)$ \\
\hline Checkup & $15(3.73 \%)$ \\
\hline
\end{tabular}

Table 2. Chief complaint(s) of the Study Population 
Table 2 describes the chief complaint of the patients examined. Most of the patient's complained of periodontal problem $[187(46.5 \%)]$, and 15 patients (3.73\%) came for regular check-up. A total of 113 (28.1\%) patients complained of pain, out of which, a majority [51 (45.1\%)] was in the dental hard tissues.

The prevalence of OMLs and the statistical significance is seen in table 3. The maximum OML seen in the

\begin{tabular}{|c|c|c|c|}
\hline Type of lesion & Frequency (\%) & $\begin{array}{c}\text { P Value (Lesion * } \\
\text { Gender) }\end{array}$ & $\begin{array}{c}\text { P Value (Lesion * } \\
\text { Age) }\end{array}$ \\
\hline Coated tongue & o8 (4.97\%) & NS & NS \\
\hline Leukoplakia & $14(8.70 \%)$ & NS & $0.002^{*}$ \\
\hline Gingivitis & $46(28.57 \%)$ & $.01^{*}$ & $0.03^{*}$ \\
\hline Linea Alba & $15(9 \cdot 32 \%)$ & NS & NS \\
\hline Tabagic Keratosis & $20(12.42 \%)$ & NS & NS \\
\hline $\begin{array}{c}\text { Tongue } \\
\text { depapillation }\end{array}$ & $06(3.73 \%)$ & NS & NS \\
\hline Traumatic Fibroma & $09(5.59 \%)$ & NS & NS \\
\hline Fordyce granules & $03(1.86 \%)$ & NS & NS \\
\hline $\begin{array}{c}\text { Oral Submucous } \\
\text { Fibrosis }\end{array}$ & $10(6.21 \%)$ & NS & NS \\
\hline Frictional Keratosis & $12(7.45 \%)$ & NS & $0.012^{*}$ \\
\hline Angular Chelitis & $5(3.11 \%)$ & NS & NS \\
\hline Leukoderma & $3(1.86 \%)$ & NS & NS \\
\hline Ankyloglossia & $7(4 \cdot 35 \%)$ & NS & NS \\
\hline Mucocele & $03(1.86 \%)$ & NS & NS \\
\hline Total & 161 & -- & -- \\
\hline
\end{tabular}

Table 3. Prevalence of OMLs in the Study Population population was gingivitis [46(28.57\%] while the prevalence of Leukoplakia was found to be $8.70 \%$ and OSMF was found to be $6.21 \%$. A significant difference was seen among gingivitis with respect to age and gender $(\mathrm{p}<.05)$, leukoplakia and frictional keratosis was seen significant in relation to gender. In all significant cases, Males were more prone to get these OMLs as compared to females. 
that females do not have much time for their dental check-ups as they are busy with their official duties and/or as a homemaker.

The results of the present study revealed that dental pain was seen among $28.1 \%$ of the population and this is in disagreement with the results of Kakoei et al., who reported a prevalence of $55.1 \%$ of toothache among their study subjects. ${ }^{13}$ The prevalence of periodontitis in the present study was $46.5 \%$ and is lower as compared to Sanjana MK et al.(83.2\%) $)^{14}$ and Greene JC (97\%) in partial agreement to Anil S et al. ${ }^{16}$ Rao $\mathrm{S}$ et al., in a sharp contrast, only reported a prevalence of $6.83 \%$ of people among their study settings to be affected with periodontitis. ${ }^{17}$ This is mainly due to differences in culture and oral hygiene maintenance practices which is different in different geographic locations.

The prevalence of OSMF i.e $6.21 \%$ is in disagreement to Jha RN et al. (1\%) 17 and Mehta FS et al..$^{18}$ and Pindborg JJ et al. ${ }^{19}(0.03 \% \text { and } 3.2 \%)^{19}$ while the prevalence of leukoplakia in the present study $(8.70 \%)$ is similar to Krishna Priya $\mathrm{M}$ et al. (5.3\%) ${ }^{1}$ and Mehta FS et al. (2.9 and $5 \%) .{ }^{20}$ With difference in geographic location, authors reports difference in prevalence of leukoplakia, which range from $0.59 \%$ (Saraswathi et al.) ${ }^{21}$ to $61.2 \%$ (Naveen-Kumar et al.). ${ }^{22}$ This can be attributed to a higher use of tobacco products in different geographic locations.

\section{CONCLUSION}

Based on the prevalence rates of the present study, we advise proper counselling sessions and need for targeted oral health drives with emphasis on tobacco cessation in the region of Delhi NCR to reduce the further incidence of such OMLs

\section{REFERENCES}

1. Krishna Priya M, Srinivas P, Devaki T. Evaluation of the prevalence of oral mucosal lesions in a population of eastern coast of South India. J Int Soc Prevent Communit Dent 2018;8:396-401.

2. Ain TS, Gowhar O, Sultan S, Tangade P. Prevalence of oral mucosal lesions and associated habits in Kashmir, India. Int J Res Med Sci 2016;4:3525-30.

3. Balaram P, Sridhar H, Rajkumar T, Vaccarella S, Herrero R, Nandakumar A, et al. Oral cancer in Southern India: The influence of smoking, drinking, paan-chewing and oral hygiene. Int $J$ Cancer 2002;98:440-5.
4. Kaur J, Jain DC. Tobacco control policies in India: Implementation and challenges. Indian J Public Health 2011;55:220-7.

5. Solanki S, Dahiya R, Blaggana A, Yadav R, Dalal S, Bhayana D. Periodontal health status, oral mucosal lesions, and adverse oral habits among rubber factory workers of Bahadurgarh, Haryana, India. Indian J Dent Sci 2019;11:7-11.

6. Jha P, Chaloupka FJ, eds . Curbing the Epidemic: Governments and the Economics of Tobacco Control. Washington DC: The World Bank; 1999.

7. Mohan P, Lando HA, Panneer S. Assessment of Tobacco Consumption and Control in India. Indian Journal of Clinical Medicine 2018;9:1-8.

8. IBM Corp. Released 2012. IBM SPSS Statistics for Windows, Version 21.o. Armonk, NY: IBM Corp.

9. Kamble KA, Guddad SS, Nayak AG, Suragimath A, Sanade AR. Prevalence of Oral Mucosal Lesions in Western Maharashtra: A Prospective Study. J Indian Acad Oral Med Radiol 2017;29:282-7

10. Mathew AL, Pai KM, Sholapurkar AA, Vengal M. The prevalence of oral mucosal lesions in patients visiting a dental school in Southern India. Indian J Dent Res. 2008 Apr-Jun;19(2):99-103.

11. Toum SEL, Cassia A, Bouchi N, Kassab I. Prevalence and Distribution of Oral Mucosal Lesions by Sex and Age Categories: A Retrospective Study of Patients Attending Lebanese School of Dentistry. International Journal of Dentistry 2008;2018:4030134

12. l-Mobeeriek A, Al-Dosari AM. Prevalence of oral lesions among Saudi dental patients. Ann Saudi Med 2009;29:365-8.

13. Kakoei SH, Parirokh M, Nakhaee N, Jamshidshirazi F, Rad M, Kakooei S. Toothache Prevalence and Associated Factors: A Population-Based Study in Southeast Iran. Iran Endod J. 2013; 8(3): 123-8.

14. Sanjana MK, Mehta FS, Docto RH, Baretto MA. Mouth hygiene habits and their relation to periodontal disease. J Dent Res. 1956;35:645-47.

15. Greene JC. Periodontal disease in India: report of an epidemiological study. J Dent Res. 1960;39:302-12.

16. Anil S, Hari S, Vijayakumar T. Periodontal conditions of a selected population in Trivandrum District, Kerala. India Community Dent Oral Epidemiol. 1990;18(6):325.

17. Jha R N, Kalyani P B, Savarkar S V. Incidence rate of oral submucous fibrosis (OSMF) and its etiology in patients visiting Government Dental College and Hospital, Jamnagar (GDCH, Jamnagar). J Integr Health Sci 2014;2:11-5. 
18. Mehta FS, Gupta PC, Daftary DK, Pindborg JJ, Choksi SK. An epidemiologic study of oral cancer and precancerous conditions among 101,761 villagers in Maharashtra, India. Int J Cancer 1972;10:134-41.

19. Pindborg JJ, Mehta FS, Gupta PC, Daftary DK. Prevalence of oral submucous fibrosis among 50,915 Indian villagers. Br J Cancer 1968;22:646-54.

20. Mehta FS, Hammer JE. Tobacco-related Oral Mucosal Lesions and Conditions in India. Guide for Dental Students, Dentists, and Physicians. Bombay: Basic Dental Research Unit. Tata Institute of Fundamental Research; 1993
21.Saraswathi TR, Ranganathan K, Shanmugam S, Sowmya R, Narasimhan PD, Gunaseelan R, et al. Prevalence of oral lesions in relation to habits: Crosssectional study in South India. Indian J Dent Res 2006;17:121-5.

22. Naveen-Kumar B, Tatapudi R, Sudhakara-Reddy R, Alapati S, Pavani K, Sai-Praveen KN, et al. Various forms of tobacco usage and its associated oral mucosal lesions. J Clin Exp Dent 2016;8:e172-7.
Source of support: Nil, Conflict of interest: None declared
Cite this article as:

Kaur S, Singh A, Singh R. A Retrospective Analysis of the Prevalence of Distribution of Oral Mucosal Lesions (OMLs) among the People of Delhi NCR. Int Healthc Res J. 2019;3(4):154-158. https://doi.org/10.26440/IHRJ/0304.07258

\section{AUTHOR AFFILIATIONS:}

\section{MDS (Oral Medicine and Radiology), Consultant Dental Surgeon, Delhi NCR}

BDS, Consultant Dental Practitioner, Faridabad

BDS, Consultant Dental Surgeon, Meerut

Corresponding Address:

Dr. Simran Kaur

401, Tower 10

Grand Forte Society

Sigma IV

Greater Noida

uppalsimran940[at]gmail[dot]com 